\title{
ENSINO DOS ESPORTES NA ESCOLA PÚBLICA E O DESENVOLVIMENTO DO PENSAMENTO CRÍTICO DE ALUNOS DO ENSINO MÉDIO
}

Daniel Teixeira Maldonado, Universidade São Judas Tadeu - USJT, São Paulo, São

Paulo-Brasil

\section{RESUMO}

Descrevo uma experiência pedagógica nas aulas de Educação Física realizada durante o $2^{\circ}$ semestre de 2014, para alunos do Ensino Médio de uma escola técnica estadual localizada na zona leste do município de São Paulo, em que os esportes foram tematizados com a intenção de estimular o pensamento crítico dos estudantes. Por meio dessa experiência pedagógica na qual os alunos puderam vivenciar; compreender, refletir, analisar, debater e produzir conhecimento sobre essa manifestação da cultura corporal de movimento, percebeu-se progresso no desenvolvimento do pensamento crítico deles sobre o tema.

Palavras - Chave: Educação Física escolar; Esportes; Pensamento crítico.

\section{EDUCATION SPORTS PUBLIC SCHOOL AND THOUGHT OF DEVELOPMENT OF CRITICAL HIGH SCHOOL STUDENTS}

\begin{abstract}
Describe an educational experience in physical education classes held during the 2 nd half of 2014, for high school students of a state technical college located on the east side of São Paulo, where sports were themed with the intention of stimulating critical thinking of students. Through this learning experience in which students were able to experience, understand; reflect, analyze, discuss and produce knowledge about this manifestation of the culture of body movement, it was noted progress in the development of their critical thinking on the subject.
\end{abstract}

Key - Words: Physical Education; Sports; Critical thinking.

\section{EDUCACIÓN DEPORTIVA ESCUELA PÚBLICA Y PENSAMIENTO DE DESARROLLO DE CRÍTICOS ESTUDIANTES DE SECUNDARIA}

\section{RESUMEN}

Describa una experiencia educativa en clases de educación física han mantenido en el segundo semestre de 2014, para los estudiantes de secundaria de una escuela técnica estatal ubicado en el lado este de São Paulo, donde el deporte se temáticas con la intención de estimular el pensamiento crítico de los estudiantes. A través de esta experiencia de aprendizaje en el que los estudiantes fueron capaces de experimentar, comprender, reflexionar, analizar, discutir y producir conocimiento sobre esta manifestación de la Conexões: revista da Faculdade de Educação Física da UNICAMP, Campinas, v. 13, n. 3, p. 213-230, jul./set. 2015. ISSN: $1983-9030$ 
cultura de los movimientos del cuerpo, se observó el progreso en el desarrollo de su pensamiento crítico sobre el tema.

Palabras - Clave: Educación Física; Deportes; Pensamiento crítico. 


\section{INTRODUÇÃO}

O esporte nas escolas foi ensinado por muito tempo somente na dimensão procedimental dos conteúdos. Os professores de Educação Física costumavam ensinar as técnicas, os fundamentos, as táticas e as regras dos principais esportes coletivos e individuais que são praticados na nossa cultura e transmitidos pela mídia televisiva no Brasil.

A partir do lançamento dos Parâmetros Curriculares Nacionais da Educação Física, iniciou-se uma discussão no meio acadêmico enfatizando que os esportes e as outras manifestações da cultura corporal de movimento (lutas, ginásticas, danças, jogos e brincadeiras) também deveriam ser ensinados contemplando as dimensões conceituais e atitudinais dos conteúdos.

Nessa lógica, a Educação Física ensinada nas escolas passou a ser um componente curricular e ultrapassou o ensino dos temas da cultura corporal na dimensão procedimental. O professor começou a pensar nos conceitos que estão ligados aos procedimentos selecionados e nas reflexões que possam causar mudanças de atitudes dos alunos em relação aos conteúdos explorados nas aulas. ${ }^{1}$

$\mathrm{Na}$ década de 80 foram elaboradas diferentes propostas pedagógicas e os Parâmetros Curriculares Nacionais que ainda estão presentes na literatura brasileira (Betti, ${ }^{2}$ Brasil, $^{3}$ Broto, ${ }^{4}$ Soares et al., ${ }^{5}$ Freire, ${ }^{6}$ Guedes, ${ }^{7}$ Kunz,${ }^{8}$ Le Boulch, ${ }^{9}$ Tani et al. ${ }^{10}$ ), proporcionando diversas reflexões nos professores que ensinam no "chão das escolas", embora não exista consenso nessas propostas sobre a necessidade de tratar os conteúdos da cultura corporal nessas diferentes e complementares dimensões. Quando comparamos as diferentes propostas, percebemos que elas se diferenciam pelos objetivos declarados e pela forma como os conteúdos são trabalhados. ${ }^{11}$

Influenciados por todas as discussões e debates realizados pelos docentes de Educação Física que discutem os currículos da escola, González e Fenstesrseifer ${ }^{12}$ mencionam que a Educação Física passou a ser um componente curricular com as mesmas responsabilidades dos outros componentes presentes na escola. Dessa forma, essa disciplina escolar passou a possuir a finalidade de formar pessoas com consciência crítica para agir com autonomia 
em relação às manifestações da cultura corporal de movimento e munir o sujeito de possibilidades de se tornar um cidadão.

Portanto, entre as diferentes propostas pedagógicas para a Educação Física Escolar, nos identificamos com aquelas que defendem que sua finalidade é formar pessoas com pensamento crítico para agir com autonomia em relação às manifestações da cultura corporal de movimento, e com a consciência voltada para a formação e o exercício da cidadania.

Compreendemos o pensamento crítico de acordo com a perspectiva de Libâneo ${ }^{13}$. Segundo ele, o ensino em uma perspectiva crítica se preocupa com a democratização do conhecimento historicamente acumulado para todas as crianças e adolescentes que frequentam a escola pública, valorizando a forma de expressão desses alunos, lutando para que esses jovens se comuniquem bem, desenvolvam o gosto pelos estudos, dominem o saber escolar e se organizem como coletividade. Os docentes que ensinam nessa perspectiva buscam proporcionar aos discentes o saber e o saber-fazer críticos como condição para sua participação na vida social e na luta pela melhoria de suas condições de vida.

Desenvolver o pensamento crítico está vinculado a um processo de democratização da escola pública, levada a efeito por meio da ampliação das oportunidades educacionais, difusão dos conhecimentos e sua reelaboração crítica, aprimoramento da prática educativa escolar visando à ampliação do repertório cultural e científico dos alunos. ${ }^{14}$

Ao atuar na escola pública no ano de 2014 ensinando o componente curricular de Educação Física para alunos do Ensino Médio, realizamos diversas reflexões com os discentes pautadas nas dimensões conceituais e atitudinais dos conteúdos, tendo como principal objetivo estimular o pensamento crítico desses jovens para que no futuro eles possam atuar como cidadãos críticos e participativos na transformação da sociedade contemporânea.

Nesse sentido, nosso objetivo com este texto foi analisar e discutir uma experiência didática onde os esportes foram ensinados enfatizando as dimensões conceituais e Conexões: revista da Faculdade de Educação Física da UNICAMP, Campinas, v. 13, n. 3, p. 213-230, jul./set. 2015. ISSN: $1983-9030$ 
atitudinais dos conteúdos, e mostrar sua relação com o desenvolvimento do pensamento crítico dos alunos a respeito da cultura corporal de movimento. Faremos as nossas reflexões sobre os esportes a partir de charges realizadas pelos alunos de temas que foram discutidos em aula e achamos que devem estar presentes em todas as aulas de Educação Física dentro do ambiente escolar.

\section{MÉTODO}

Realizamos um relato de experiência de uma prática pedagógica desenvolvida em uma escola técnica estadual, localizada na zona leste da cidade de São Paulo, com alunos do $1^{\circ}$ e $2^{\circ}$ anos do ensino médio, entre os meses de agosto e dezembro do ano de 2014. Embasamos-nos na etnografia para coletarmos os dados no cotidiano escolar. Utilizamos diários de campo e utilizamos as charges elaboradas pelos alunos durante as aulas para expressar nossas experiências nesse artigo.

A etnografia é uma metodologia de pesquisa que vem sendo muito utilizada nos estudos realizados pelos pesquisadores que se preocupam com questões educacionais. Esse tipo de pesquisa qualitativa também vem sendo utilizado em projetos de inovação pedagógica, já que possibilita uma relação bastante interativa entre o sujeito e o objeto da investigação. É nessa linha que o sujeito que investiga alcança o papel de redescobridor da cultura que vivencia cotidianamente. ${ }^{15}$

Portanto, a etnografia é uma importante metodologia para compreender questões relacionadas com a escola, podendo ser um instrumento satisfatório para que os professores possam produzir conhecimento a partir da prática cotidiana e refletir sobre a sua intervenção nos ambientes escolares, além de sistematizá-la e torná-la pública. ${ }^{15}$ Nesse sentido, decidimos mencionar a nossa experiência de tematizar os esportes para os nossos alunos, enfatizando as dimensões conceituais e atitudinais dos conteúdos e o desenvolvimento do pensamento crítico.

\section{DESENVOLVIMENTO DA PRÁTICA PEDAGÓGICA}

O primeiro tema que discutimos que possui estreita relação com os conteúdos atitudinais foi o preconceito contra a mulher no esporte. Nas nossas reflexões com os discentes relembramos alguns casos de mulheres que sofreram discriminação no esporte. Um dos Conexões: revista da Faculdade de Educação Física da UNICAMP, Campinas, v. 13, n. 3, p. 213-230, jul./set. 2015. ISSN: $1983-9030$ 
casos discutidos ocorreu nesse ano onde uma árbitra que errou um lance de impedimento em um jogo do São Paulo e logo foi afastada das suas funções por esse erro. Discutimos com os alunos que diversos homens erram lances parecidos todos os dias e não tomam punições com esse grau de severidade pelos seus erros. Também discutimos casos de atletas que são convidadas diariamente para se despir em revistas masculinas e daquelas meninas que entram com os atletas em campo e são tratadas pelos homens que torcem no estádio apenas como objeto sexual. Ainda discutimos sobre as dificuldades do futebol feminino no Brasil, mesmo tendo a melhor jogadora do mundo em nosso país. A seguir mostraremos uma das charges realizadas por um aluno que demonstra bem essa realidade do machismo existente no esporte brasileiro.

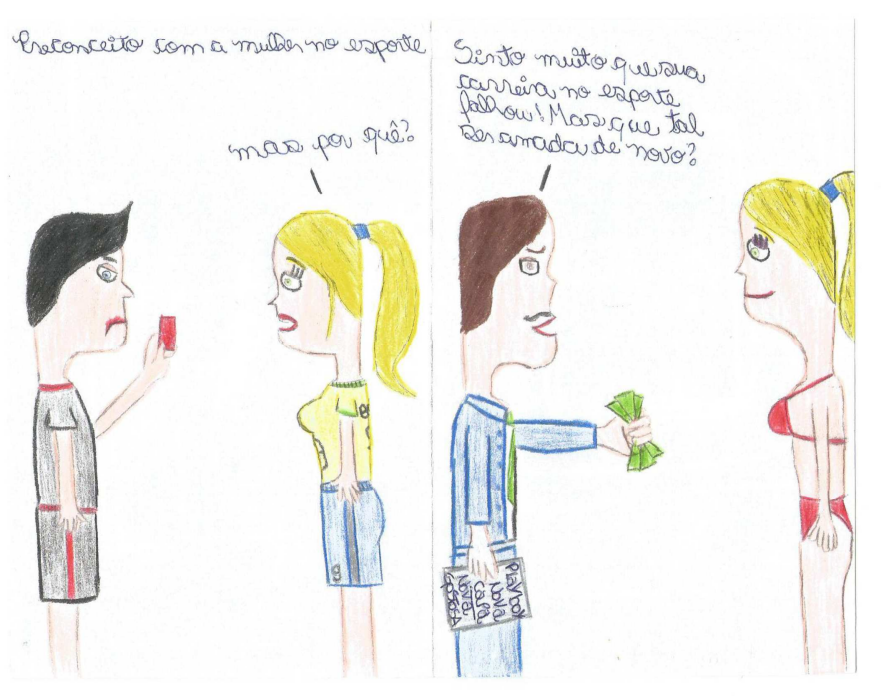

Figura 1: Preconceito contra a mulher no esporte.

Outro conteúdo atitudinal que foi discutido nas aulas esteve relacionado com o preconceito racial existente no esporte. Nas reflexões que realizamos com os discentes relembramos que alguns esportes possuem poucas pessoas de pele negra os praticando, como é o caso do tênis, da natação e dos diferentes tipos de ginástica. Ainda nesse ponto relembramos o próprio preconceito que os atletas de futebol de pele negra sofreram e sofrem no Brasil, destacando recentemente os casos da banana que os espanhós jogaram para um atleta brasileiro que joga no Barcelona e do goleiro santista que foi chingado de macaco por diversos torcedores do Grêmio em um jogo realizado no sul do Brasil.

Conexões: revista da Faculdade de Educação Física da UNICAMP, Campinas, v. 13, n. 3, p. 213-230, jul./set. 2015. ISSN: 1983-9030 
Percebemos durante as nossas aulas que os discentes conheciam os casos de preconceito racial no esporte, mas a sua opinião era formada apenas pela discurso da mídia televisiva, que muitas vezes não realiza essas discussões com a profundidade que elas merecem, ou apenas espetacularizam os fatos para aumentarem a sua audiência. Abaixo, segue uma das charges dos nossos alunos que nos faz refletir sobre o preconceito racial existente ainda no esporte brasileiro.

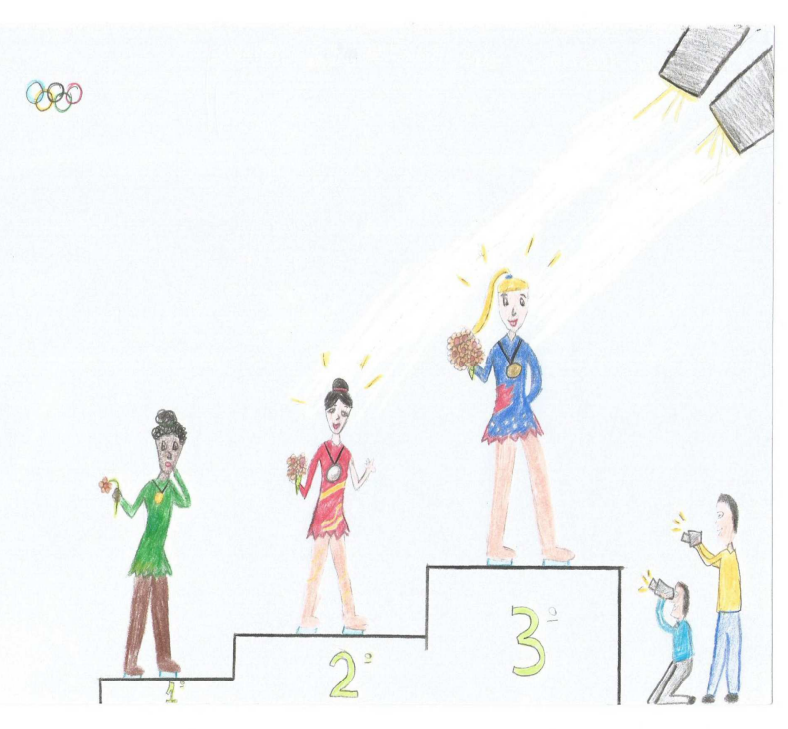

Figura 2: Preconceito racial no esporte.

Também discutimos com os nossos alunos do Ensino Médio porque existem esportes que são mais realizados pelas pessoas que possuem uma situação econômica mais confortável e outros esportes que são realizados na maioria das vezes por pessoas mais pobres. Ao realizar essas discussões mostramos o quanto é caro comprar uma raquete de tênis profissional, uma arma (espada, sabre e florete) e a roupa usada pelos praticantes de esgrima, pagar uma academia para realizar natação todos os meses ou ainda usufruir de uma roupa para praticar algumas lutas como o judô.

Em nossas reflexões perguntamos aos alunos se eles conheciam espaços de lazer na sua comunidade que ofereciam algumas dessas praticas esportivas mencionadas anteriormente ou se eles já tinham aprendido na escola algumas dessas modalidades e a maioria dos Conexões: revista da Faculdade de Educação Física da UNICAMP, Campinas, v. 13, n. 3, p. 213-230, jul./set. 2015. ISSN: 1983-9030 
discentes disseram que não conheciam nenhum local que ensinasse esses esportes e que nunca tinham discutidos essas questões na escola. Eles também reconheceram que muitos colegas jogavam futebol por ser uma pratica esportiva que pode ser realizada com pouco recurso material, além da influência da mídia que só fala o tempo inteiro dessa pratica corporal nos programas esportivos. Um dos alunos se preocupou em realizar a sua charge sobre esse tema (FIGURA 3).

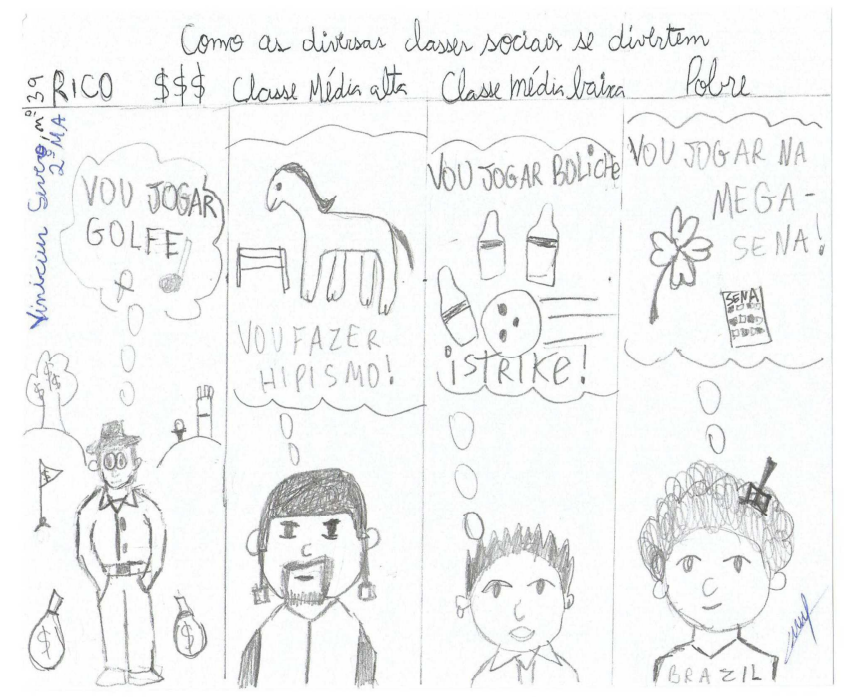

Figura 3: Preconceito de ordem econômica no esporte.

A orientação sexual dos atletas é outro tema que foi tratado em nossas aulas e todas as vezes que conversamos sobre essa questão as emoções se afloram entre os discentes. Em aulas expositivas proporcionamos a possibilidade de realizar debates sobre aqueles atletas que assumiram a sua homossexualidade e foram hostilizados no esporte, como foi o caso do jogador Michael de vôlei, pois, durante uma partida em que ele jogava, mais de vinte e cinco mil pessoas gritaram "bicha" dentro de um ginásio para atingi-lo. Perguntamos aos alunos se essas atitudes dos torcedores estavam relacionadas com o palco esportivo ou se isso realmente era um preconceito contra a orientação sexual das pessoas.

Esse é outro tema que está sendo discutido pelas novelas televisivas e sempre é tratado de forma superficial. Até mesmo os candidatos à presidência do Brasil no ano de 2014 Conexões: revista da Faculdade de Educação Física da UNICAMP, Campinas, v. 13, n. 3, p. 213-230, jul./set. 2015. ISSN: 1983-9030 
realizaram esse debate de forma acalorada e sabemos que algumas religiões também acabam estimulando o preconceito e a homofobia, por tratarem as pessoas que decidem se relacionar com outras pessoas do mesmo sexo como seres que não seguem a bíblia.

Essa temática precisa ser discutida nas aulas de Educação Física na escola, principalmente quando os docentes se propõem a ensinar os esportes se pautando nas três dimensões do conteúdo e querem desenvolver o pensamento crítico nos seus alunos. Importante ressaltar que tratamos o tema com o objetivo de estimular a reflexão dos alunos sobre a importância de eliminar o preconceito contra os homossexuais no esporte. A seguir segue uma charge de um docente que se preocupou de retratar a realidade desse tipo de preconceito no esporte.

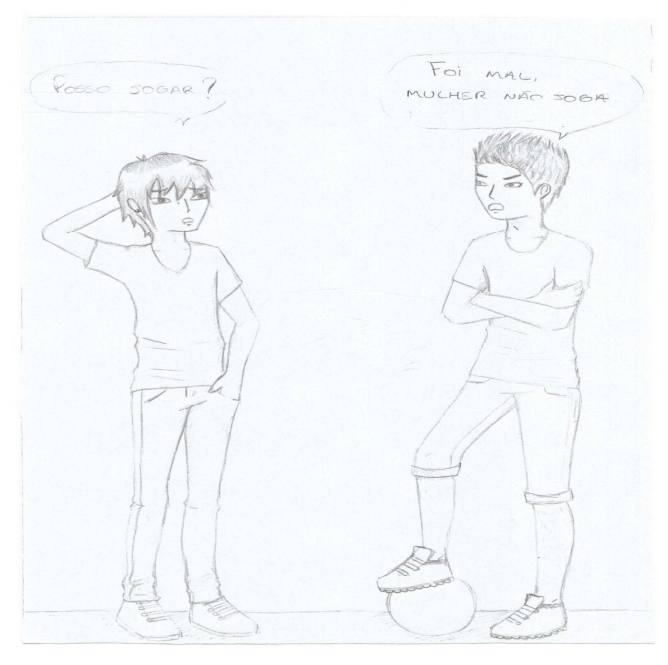

Figura 4: Preconceito contra o homossexual no esporte.

Por incrível que possa parecer o preconceito com as pessoas que possuem algum tipo de deficiência ainda está presente em nossa sociedade e por consequência no esporte. Ao realizar essas discussões em nossas aulas percebemos que essa era uma questão de pouca preocupação dos nossos alunos, pois eles não conheciam os esportes para pessoas com deficiência e não se preocupavam sobre a infraestrutura existente para que essas pessoas possam trabalhar, se divertir e viver como qualquer outro cidadão. 
Mostramos alguns esportes para deficientes para os alunos (basquete para cadeirantes, vôlei sentado, rugby em cadeira de rodas, goalball, futebol de 5, etc..) e assistmos alguns vídeos retirados do youtube sobre esses esportes, além de realizá-los de forma adaptada nas aulas práticas. Nosso principal objetivo era mostrar aos alunos que as pessoas com deficiência possuem um tipo de limitação e que as pessoas que não possuem uma deficiência especifíca também possuem dificuldades para realizar várias tarefas diárias, ou seja, nós somos seres humanos com dificuldades e qualidades e não precisamos de rótulos, apenas de respeito. A charge abaixo realizada por um dos nossos alunos demostra bem esse preconceito que ainda existe sobre as pessoas com deficiência que praticam esportes.

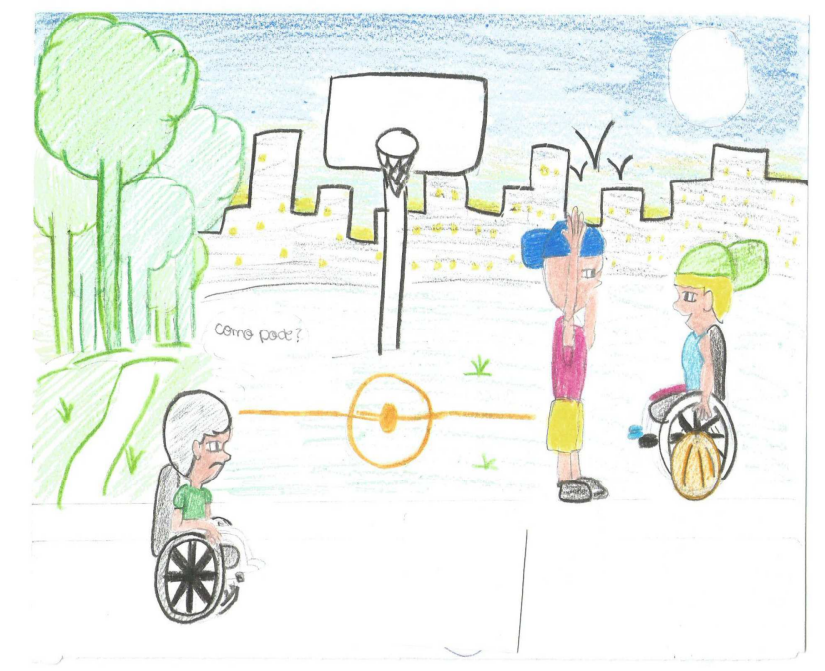

Figura 5: Preconceito contra a pessoa com deficiência no esporte.

Já realizando uma discussão de ordem mais conceitual refletimos com os nossos alunos se realmente esporte pode ser considerado saúde. Mostramos diversos atletas de alto nível dizendo que sentem muita dor durante as partidas esportivas, acabam adquirindo diversas lesões e necessitam realizar diversas cirurgias para se manter no esporte. Além disso, pontuamos muitos atletas de alto nível que já foram flagrados no teste antidoping por utilizar anabolizantes ou outras drogas. 
Nesse momento mostramos diversos efeitos colaterais da utilização dos anabolizantes (calvície, acne, esterilidade, impotência sexual, apodrecimento dos músculos, doenças renais, câncer e em casos mais severos a morte). Retiramos fotos da internet e alertamos esses jovens sobre a gravidade desses efeitos colaterais não só no uso do esporte, mas também para pessoas que os utilizam por estética, principalmente em academias de ginástica. Muitas charges foram realizadas pelos discentes retratando os efeitos colaterais do uso de anabolizantes pelos atletas e colocamos nesse texto aquela que achamos uma das mais inteligentes em relação ao tema discutido.

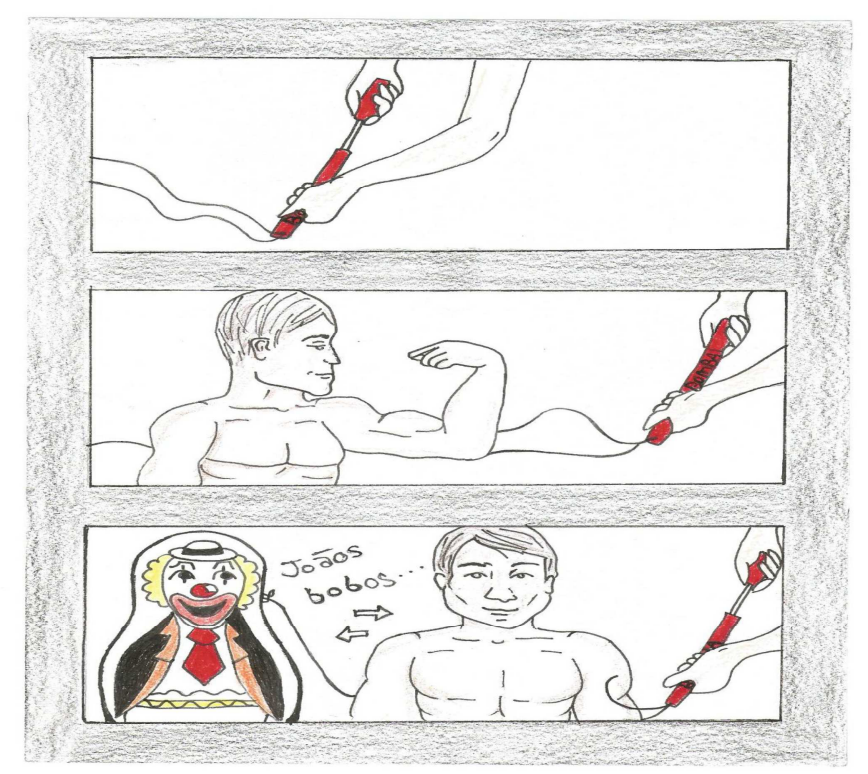

Figura 6: Utilização de anabolizanres no esporte.

A violência no esporte foi mais um tema que discutimos com os jovens que participaram das aulas de Educação Física. Nos últimos anos houveram diversos casos de violência dentro e fora dos campos e ginásios. As torcidas organizadas no futebol brigam entre elas em praticamente todos os finais de semana e novamente a mídia televisiva trata esse tema de forma superficial. Os atletas também brigam entre eles dentro dos estádios em muitos jogos e essas atitudes estimulam os torcedores a brigarem nas ruas. 
Essa questão da violência não é uma realidade apenas brasileira, pois em diversas partes do mundo os torcedores brigam e formam facções com os nomes dos times que torcem com a intenção de continuar as brigas e as discussões. Os comentaristas esportivos muitas vezes fomentam essas brigas quando fazem alguns comentários antiéticos que inflamam essas pessoas mais exaltadas.

Infelizmente, as pessoas que gostam de esporte e gostariam de assistir os jogos nos gramados acabam se afastando dos estádios de futebol, fato esse comprovado pela média de público que frequentam as competições esportivas no Brasil. Muitos alunos mencionaram o medo que as suas famílias possuem de frequentar esses estádios. A charge abaixo relata bem a realidade de violência que ainda existe no esporte e quanto isso afasta muitos torcedores de assistirem os esportes que gostam ao vivo.

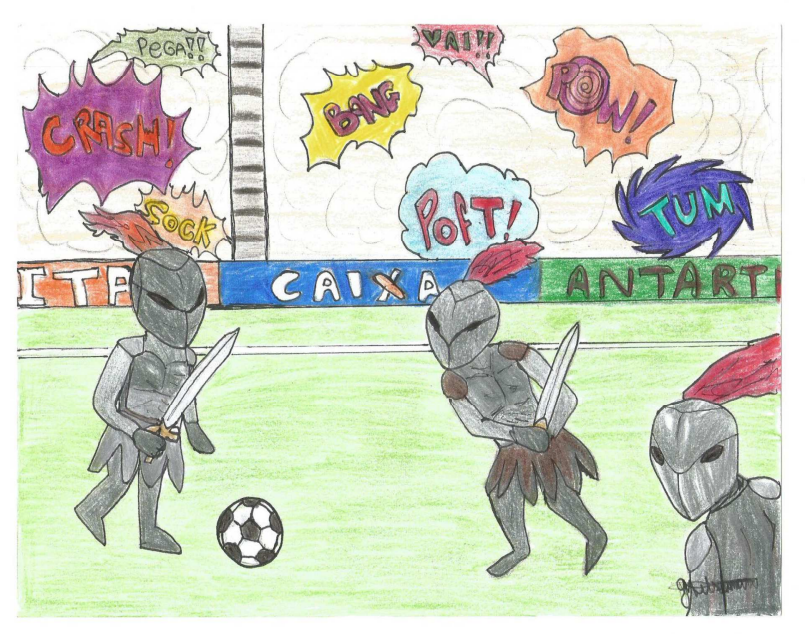

Figura 7: Violência no esporte.

A Copa do Mundo no Brasil também foi mencionada durante as discussões sobre o esporte. Ministramos aula no bairro em que foi contruído o estádio que recebeu os jogos do Brasil em São Paulo durante o evento da FIFA e isso estimulou cada vez mais as nossas reflexões. Discutimos com os alunos a realidade dos postos de saúde que eles frequentam, os espaços de lazer que eles possuem na sua comunidade para realizar esportes, a mobilidade urnaba e a qualidade de vida existente naquele bairro, com a intenção de relacionar a realidade vivenciada por as suas famílias e os gastos realizados com a realização desse evento no Brasil.

Conexões: revista da Faculdade de Educação Física da UNICAMP, Campinas, v. 13, n. 3, p. 213-230, jul./set. 2015. ISSN: 1983-9030 
Percebemos que os jovens já tinham uma opinião crítica sobre o assunto e muitos se posicionaram contra a realização do evento em um país pobre e com diversos problemas sociais, mas essas discussões foram realizadas depois da Copa e o resultado do Brasil na reta final do evento pode ter influenciado na opinião dos alunos. Mas, de qualquer forma, seria impossível ter como objetivo desenvolver o pensamento crítico dos estudantes em relação ao esporte sem tocar nesse assunto. A próxima charge que será apresentada relatou bem a opinião dos alunos em relação ao evento realizado no nosso país.

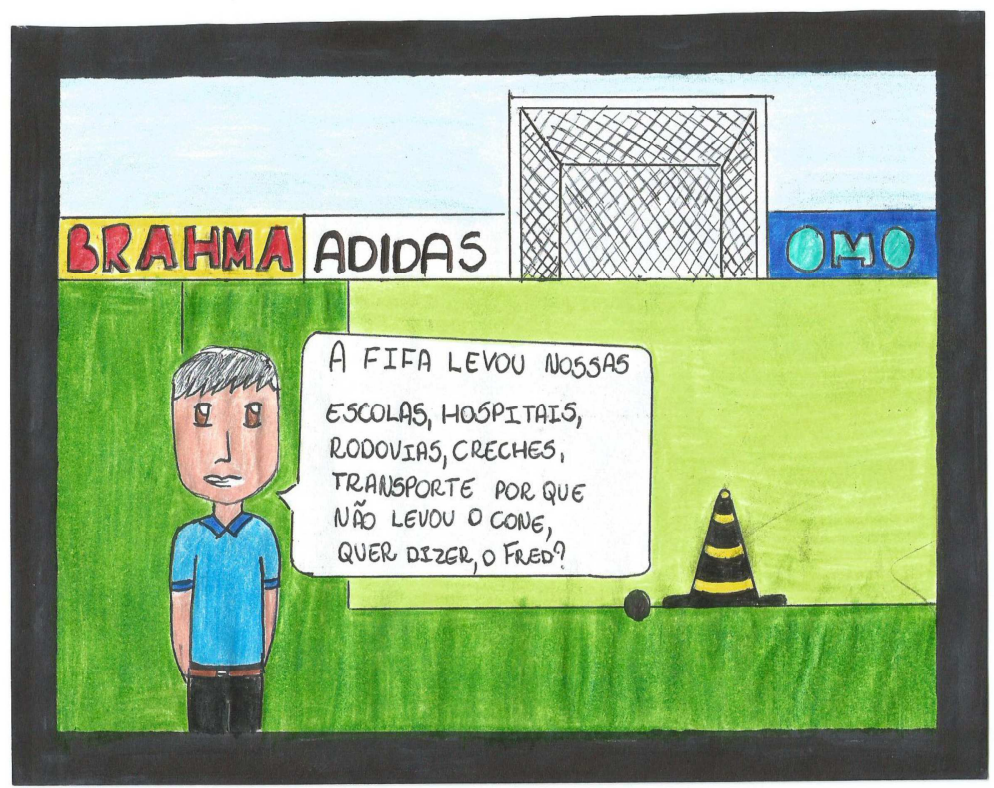

Figura 8: Gastos públicos no esporte.

\section{REFLEXÕES DIDÁTICAS SOBRE A EXPERIÊNCIA}

Tivemos algumas dificuldades para discutir os conteúdos conceituais e atitudinais mencionados nesse texto com os nossos alunos, principalmente porque nas experiências anteriores que esses jovens possuíam de Educação Física, eles acabavam tendo apenas aulas práticas e aprendiam apenas os fundamentos e as regras dos esportes que eram ensinados durante as aulas. Durante os primeiros dias das nossas aulas, houve certo desconforto de alguns alunos que queriam praticar esportes e não refletir sobre os mesmos. 
Sabemos que aqueles professores de Educação Física que quiserem propor discussões parecidas com aquelas que realizamos com os nossos alunos também irão encontrar essas mesmas dificuldades, mas muitos estudos realizados com professores que atuam em escolas públicas e inovam na sua prática pedagógica foram publicados nos últimos anos. Esses autores tiveram como objetivo compartilhar as suas experiências pedagógicas para que outros docentes pudessem reconhecer a possibilidade de trabalhar com conteúdos de ordem conceitual e atitudinal nas suas aulas, formando alunos mais críticos e participativos durante as aulas de Educação Física. Esses relatos de prática mostram experiências pedagógicas com atletismo, voleibol, ginásticas, lutas, danças e futebol. ${ }^{16-23}$

Portanto, esperamos que as nossas reflexões didáticas com esse texto estimulem outros docentes a planejarem conteúdos de ordem conceitual e atitudinal quando estiverem ensinando esportes em suas aulas e estimulem os seus alunos a refletirem de forma crítica sobre esses temas, para que realmente possamos viver em uma sociedade mais democrática e justa em todos os setores, inclusive no esporte.

\section{CONSIDERAÇÕES FINAIS}

Consideramos que os professores de Educação Física que se preocupam em ensinar os esportes dentro das escolas precisam debater com os alunos o preconceito com a mulher, com as pessoas de pele negra, com os homossexuais, com as pessoas com menor poder aquisitivo e com as pessoas com necessidades especiais que praticam esportes. Além dessas questões de ordem atitudinal, os docentes também podem realizar debates sobre a violência no esporte e os gastos públicos realizados para construir palcos que iram receber competições esportivas. Conteúdos de ordem conceitual, como a discussão se esporte é saúde também precisam ser desenvolvidos durante as aulas.

Obviamente que as aulas de Educação Física na escola não devem ser apenas teóricas e os discentes precisam vivenciar todas as manifestações da cultura corporal de movimento durante os anos de escolarização, mas, os docentes também precisam começar a se preocupar com outros temas contemporâneos que surgem ao redor dessas manifestações. Nesse texto discutimos especificamente como podemos debater esses temas dentro do esporte.

Conexões: revista da Faculdade de Educação Física da UNICAMP, Campinas, v. 13, n. 3, p. 213-230, jul./set. 2015. ISSN: 1983-9030 
Desenvolver o pensamento crítico dos alunos é o objetivo central das aulas de Educação Física dentro do contexto da escola pública e os professores precisam utilizar diferentes estratégias para alcançar essa meta com os seus discentes. Para esse objetivo ser alcançado, o docente também necessita estar antenado nos acontecimentos referentes às manifestações da cultura corporal de movimento, para que ele possa debater e discutir com os alunos os aspectos mais contemporâneos dos conteúdos que ele ensina na escola.

Possibilitar uma educação crítica dentro do ambiente escolar poderá melhorar as relações humanas em um futuro próximo, tornando a nossa sociedade menos desigual e mais justa, além de munir os jovens com conhecimento para lutar pelas melhorias que a nossa sociedade necessita. Todas as disciplinas da escola deveriam seguir por esse caminho, inclusive a Educação Física. Ensinar o esporte de forma crítica significa compreender e transformar essa manifestação da cultura corporal de movimento com a intenção de alcançar a nossa principal meta que é criar um mundo mais justo em todos os setores da sociedade.

\section{REFERÊNCIAS}

${ }^{1}$ DARIDO, S. C. et al. A Educação Física, a formação do cidadão e os Parâmetros Curriculares Nacionais. Revista Paulista de Educação Física, São Paulo, v. 15, n. 1, p. 17-32, jan./jun. 2001.

${ }^{2}$ BETTI, M. Educação Física e sociedade: a Educação Física na escola brasileira de $1^{\circ}$ e $2^{\circ}$ graus. 2. ed. São Paulo: Hucitec, 2009.

${ }^{3}$ BRASIL. Ministério da Educação e Cultura. Secretaria de Educação Fundamental. Parâmetros Curriculares Nacionais: Educação Física. Brasília, 1998

${ }^{4}$ BROTTO, F. O. Jogos cooperativos: se o importante é competir, o fundamental é cooperar. São Paulo: Cepeusp, 1995. 
${ }^{5}$ SOARES, C. L. et al. Metodologia do ensino de Educação Física. São Paulo: Cortez, 1993.

${ }^{6}$ FREIRE, J. B. Educação de corpo inteiro: teoria e prática da Educação Física. Campinas: Scipione, 1989.

${ }^{7}$ GUEDES, D. P. Educação para saúde mediante programas de Educação Física Escolar. Motriz, Rio Claro, v. 5, n. 1, jun. 1999.

${ }^{8}$ KUNZ, E. Transformação didático-pedagógica do esporte. 4. ed. Ijuí: Ed. da Unijuí, 2001.

${ }^{9}$ LE BOULCH, J. A educação pelo movimento: a psicocinética na idade escolar. Porto Alegre: Artes Médicas, 1983.

${ }^{10}$ TANI, G. et al. Educação Física escolar: fundamentos de uma abordagem desenvolvimentista. São Paulo: EPU, 1988.

${ }^{11}$ SILVA, S. A. P. S. Portas abertas para a Educação Física: falando sobre abordagens pedagógicas. São Paulo: Phorte, 2013.

${ }^{12}$ GONZÁLEZ, F. J.; FENSTERSEIFER, P. E. Entre o "não mais" e o "ainda não": pensando saídas para o não lugar da EF escolar II. Cadernos de Formação RBCE, v. 1, n. 2, p. 10-21, 2010.

${ }^{13}$ LIBÂNEO, J. C. Democratização da escola pública: a pedagogia crítico-social dos conteúdos. 9. ed. São Paulo: Loyola, 1990.

14___. Didática. 2. ed. São Paulo: Cortez, 2013.

Conexões: revista da Faculdade de Educação Física da UNICAMP, Campinas, v. 13, n. 3, p. 213-230, jul./set. 2015. ISSN: 1983-9030 
${ }^{15}$ MOLINA NETO, V.; TRIVIÑOS, A. N. S. A pesquisa qualitativa na Educação Física: alternativas metodológicas. In: MOLINA NETO, V. Etonografia: opção metodológica para alguns problemas de investigação no âmbito da Educação Física. 3. ed. Porto Alegre: Sulina, 2010.

${ }^{16}$ BARROSO, A. L. R.; DARIDO, S. C. Voleibol escolar: uma proposta de ensino na dimensão conceitual, procedimental e atitudinal do conteúdo. Revista Brasileira de Educação Física e Esporte, v. 24, n. 2, p. 179-194, abr.jun. 2010.

${ }^{17}$ MALDONADO, D. T.; BOCCHINI, D. Prática pedagógica diferenciada nas aulas de Educação Física: a ginástica na escola pública. Coleção Pesquisa em Educação Física, v. 12, n. 1, p. 165-172, 2013.

18__. As três dimensões do conteúdo na Educação Física: tematizando as lutas na escola pública. Conexões: revista da Faculdade de Educação Física da UNICAMP, Campinas, v. 11, n. 4, p. 195-211, 2013.

${ }^{19}$ MALDONADO, D. T.; BOCCHINI, D. Educação Física escolar e as três dimensões do conteúdo: tematizando as danças na escola pública. Conexões: revista da Faculdade de Educação Física da UNICAMP, Campinas, v. 12, n. 1, p. 181-200, 2014.

20 Educação Física escolar e as três dimensões do conteúdo: tematizando os esportes na escola pública. Conexões: revista da Faculdade de Educação Física da UNICAMP, Campinas, v. 12, n. 2, p. 147-165, 2014

${ }^{21}$ MASCARA, D. I.; CHIMINAZZO, J. G. C.; LIMA, N. M. O futebol da escola: construção de uma proposta baseada nas três dimensões dos conteúdos. Pulsar, v. 5, n. 1, 2013.

Conexões: revista da Faculdade de Educação Física da UNICAMP, Campinas, v. 13, n. 3, p. 213-230, jul./set. 2015. ISSN: 1983-9030 
${ }^{22}$ MATTHIESEN, S. Q.; SILVA, M. F. G.; SILVA, A. C. L. Motriz, Rio Claro, v. 14, n. 1, p. 96-104, 2008.

${ }^{23}$ RODRIGUES, H. A.; DARIDO, S. C. As três dimensões do conteúdo na prática pedagógica de uma professora de Educação Física com mestrado: um estudo de caso. Revista da Educação Física/UEM, Maringá, v. 19, n. 1, p. 51-64, 2008.

Recebido em: 12 maio 2015 Aceito em: 21 maio 2015 Contato: danieltmaldonado@yahoo.com.br 